\title{
Self-Talk and Affective Problems in College Students: Valence of Thinking and Cognitive Content Specificity
}

\author{
Esther Calvete, Ana Estévez, Covadonga Landín, Yolanda Martínez, \\ Olga Cardeñoso, Lourdes Villardón, and Aurelio Villa \\ University of Deusto
}

\begin{abstract}
The aim of this study was to develop a Self-Talk Inventory for young adults. This inventory consisted of two scales. The Negative Self-Talk Scale included three categories of selftalk (depressive, anxious, and angry thoughts) and the Positive Self-Talk Scale, three categories (minimization, positive orientation, and coping self-instructions). Participants were 982 undergraduate students (Mean age $=20.35$ years, $S D=2.16$ ). They completed the self-talk scales together with the following scales to measure symptoms of affective disorders: the Center for Epidemiological Studies Depression Scale (CES-D), the StateTrait Anxiety Inventory (STAI), and the State-Trait Anger Expression Inventory (STAXIT). Factor analyses confirmed the hypothesized structure for the Self-Talk Inventory. The relations between self-talk and symptoms of affective disorders (depression, anxiety, and anger) were also evaluated. In general, states-of-mind -SOM- ratios and negative cognitions showed a greater association with psychological symptoms than did positive cognitions. Results concerning the cognitive characteristics of depression, anxiety, and anger were mixed and partially supported the cognitive content specificity theory.
\end{abstract}

Keywords: self-talk, SOM ratios, cognitive specificity, depression, anxiety, anger

\begin{abstract}
El objetivo de este estudio fue el desarrollo de un inventario de autodiálogo para jóvenes adultos. Este inventario consistió en dos escalas. La Escala de Autodiálogo Negativo incluyó tres categorías de autodiálogo (pensamiento depresivo, ansioso, y relacionado con la ira) y la Escala de Autodiálogo Positivo otras tres (minimización, afecto positivo y autoinstrucciones de afrontamiento). Los participantes fueron 982 estudiantes (Edad Media $=20.35$ años, $D T=2.16$ ). Completaron las escalas de Autodiálogo junto con la Escala de Depresión del Centro para Estudios Epidemiológicos (CES-D), el Inventario Estado-Rasgo de Ansiedad (STAI) y el Inventario de Expresión de la Ira Estado-Rasgo (STAXI-T). Los análisis factoriales confirmaron la estructura hipotética del inventario de Autodiálogo. La relación entre autodiálogo y síntomas de trastornos afectivos (depresión, ansiedad e ira) también se evaluó. En general, la ratio de los Estados de la Mente SOM - y las cogniciones negativas mostraron una mayor asociación con los síntomas psicológicos que las cogniciones positivas. Se obtuvieron resultados mixtos acerca de las características cognitivas de la depresión, ansiedad e ira y estos apoyaron parcialmente la teoría de la especificidad del contenido cognitivo.

Palabras clave: autodiálogo, SOM ratios, especificidad cognitiva, depresión, ansiedad, ira
\end{abstract}

This research was supported by a grant from the Ministerio de Ciencia y Tecnología (Spanish Government).

Correspondence concerning this article should be addressed to Esther Calvete, Department of Psychology, University of Deusto, Apdo. 1, 48080 Bilbao (Spain); E-mail: ecalvete@fice.deusto.es 
Cognitive-behavioral models emphasize the link between inner speech and the development of affective disorders (Beck, 1976). This relation has been examined mainly from two different, but complementary, perspectives. One approach has focused on the assessment of the influence of the positive versus negative valence of thinking on psychological maladjustment. The second has emerged around the cognitive content-specificity hypothesis and has attempted to determine whether each affective disorder (i.e., depression and anxiety) is characterized by cognitions of different content.

Concerning the role of the valence, three hypotheses have been proposed: The first hypothesis suggests that positive thinking is the most predictive of psychological adjustment. Although some studies have found evidence for this position (e.g., Burnett, 1996), most have found results that support a second hypothesis that posits the greater influence of negative thinking on psychopathological disorders. Kendall (1984) called this phenomenon "the power of nonnegative thinking" and suggested that a lower frequency of negative thoughts, as opposed to the presence of positive ones, is more relevant to differentiate emotionally normal from maladapted groups. This hypothesis has received empirical support from several studies (e.g., Ronan, Kendall, \& Rowe, 1994; Treadwell \& Kendall, 1996). A third hypothesis, Schwartz and Garamoni's (1986) statesof-mind (SOM) model of cognitive balance, establishes that a specific proportion of negative-to-positive self-statements accounts for optimal emotional adjustment, and that dysfunction occurs when this ratio shifts. SOM ratios are usually obtained by dividing positive self-statement scores by positive-plus-negative self-statement scores. In a reformulated version of the SOM model, the optimal balance between positive and negative self-talk was assumed to approximate a ratio ranging from .67 to .90 (Schwartz, 1997). Although a number of studies have obtained support for this model, adjustment to the ratios proposed by Schwartz seems to depend on the method employed to assess self-talk (selfreport vs. thought-listing) and the categories of thinking evaluated (Calvete \& Cardeñoso, 2002; Ronan \& Kendall, 1997).

The influence of self-talk on psychopathology has also been examined from the cognitive specificity theory. Beck's (1976) cognitive model stipulated that each emotional disorder could be characterized by a cognitive content that is specific to that disorder. According to this theory, depression is characterized by predominance of negative cognitions in the form of pervasive, absolutistic statements about themes of loss, deprivation, failure, and personal inadequacy, whereas in anxiety, the cognitions reflect possible harm and danger in a more situational, probabilistic, and anticipatory way (Beck, Brown, Steer, Eidelson, \& Riskind, 1987; Clark, Beck, \& Brown, 1989).

Although the cognitive characteristics of anger have received less attention than those of depression and anxiety, social-cognitive models of aggression have proposed that aggressive people have distorted perceptions of others and of themselves. For example, aggressive children tend to perceive negative intentions in other people but to underestimate their own responsibility for the conflict (Dodge \& Crick, 1990). In addition, recent studies indicate that positive self-systems predict aggression (Edens, Cavell, \& Hughes, 1999).

The cognitive content-specificity hypothesis has focused on the differentiation of depression and anxiety, and a number of studies have provided at least partial support for the idea that the cognitions of anxious and depressed individuals are different (Beck et al., 1987; Clark, Beck, \& Steward, 1990; Ingram, Kendall, Smith, Donnell, \& Ronan, 1987). However, to distinguish anxious from depressive selftalk is difficult because of the overlap between anxiety and depression (Safren, Heimberg, Lerner, Warman, \& Kendall, 2000). For example, on average, self-report measures of these disorders correlate between .62 and .70 (Clark, Steer, \& Beck, 1994). Clark and Watson (1991) offered an explanation for the high positive correlation between depression and anxiety measures. On the basis of their tripartite model of anxiety and depression, they stated that these measures actually assess a large, common, nonspecific distress factor, called negative affect. This factor was defined as the extent to which a person reports feeling upset or unpleasantly aroused, distressed, fearful, hostile, and nervous. The tripartite model also posits another two dimensions, referred to as positive affect and physiological arousal. Positive affect reflects one's level of pleasant engagement with the environment and has components of well-being, energy, affiliation, and adventurousness (Clark \& Watson, 1991). According to this model, low positive affect would be unique to depression whereas physiological arousal would be relatively unique to anxiety.

A number of researches have obtained support for some of the premises of the tripartite model. For example, some studies have shown that negative affect correlates both with anxiety and depression whereas positive affect only correlates significantly with depression (Clark et al., 1994). However, the findings of Burns and Eidelson (1998) did not support the premises of the tripartite model, showing that nonspecific symptoms of depression and anxiety were phenomenologically distinct and could be combined into a cluster of negative affect symptoms. Other researchers' results allow integration of both the specificity hypothesis and the tripartite model. For example, using factor analysis on the symptoms of these disorders, a lower first-order level of analysis was found to suggest specificity, whereas a higher level of analysis supported generality (Clark et al., 1994; Steer, Clark, Beck, \& Ranieri, 1995). In addition, Jolly and Kramer (1994) found that internalizing cognitions showed a similar hierarchical arrangement.

The study of the link between self-talk and psychopathology has been determined, to some extent, by the methods of cognitive evaluation, with endorsement 
methods being the most commonly used in clinical practice as well as in cognitive-clinical research (Haaga, 1997). Usually, individuals are presented with a list of thoughts and asked to check off whether they experienced each thought or to rate how frequently the self-statements have occurred in a particular situation or period of time (Glass \& Arnkoff, 1997). Most self-talk questionnaires are administered retrospectively (see, for example, the Automatic Thoughts Questionnaire Revised-ATQ-R, Kendall, Howard, \& Hays, 1989, and the Cognitions Checklist-Anxiety-CCLA, Beck et al., 1987) and are consequently subject to problems of selective memory. A different strategy consists of presenting individuals with a series of imaginary situations and asking them to indicate the extent to which they would think each of the proposed self-statements. This method assesses self-talk concurrently and has been used in the Burnett Self-Talk Inventory (BSTI, Burnett, 1996). However, this approach might imply different processes because in the BSTI, the number of situations involved is constant for all individuals whereas in other questionnaires, it is variable and depends on the events that have happened to each person in real life (Calvete \& Cardeñoso, 2002).

Regarding the cognitive content, a number of endorsement measures of self-talk provide valence-based scores, that is, scores focused on the positive versus negative nature of inner speech (e.g., Burnett, 1996; Ingram, Kendall, Siegle, Guarino, \& McLaughlin, 1995). Questionnaires based exclusively on the valence pose the problem that, under the headings of negative and positive thoughts, cognitions of a very different nature are assessed. Nonetheless, most of the questionnaires have focused on self-talk related to some disorder (e.g., anxiety, depression, pain), and the items have frequently been obtained from the thoughts reported in clinical samples. For instance, following the contentspecificity theory, the differentiation of anxious and depressive internal dialogue has been the focus of some questionnaires such as the Anxious Self-Talk Questionnaire (ASSQ, Kendall \& Hollon, 1989), the CCL-A (Beck et al., 1987), and the Cognitions Checklist-Depression (CCL-D, Beck et al., 1987).

The use of questionnaires obtained from the thoughts of clinical populations could pose problems about content validity when they are employed in nonclinical populations. The main purpose of this research was to develop a SelfTalk Inventory for young students, who are the focus of several psychological studies about the link between thoughts and psychological adjustment. This inventory should fulfill a number of conditions: (a) The situations and the selfstatements included should be representative of actual experiences and thoughts that many students might have; (b) Representativeness and categories of thoughts should be determined by inter-rater agreement; (c) According to the cognitive specificity theory, the inventory should include categories of negative self-talk that are characteristic of anxiety, depression, and anger; and (d) Positive and negative self-talk should be represented by an equal number of selfstatements in order to allow estimation of SOM ratios and contrasting the hypotheses about the valence of self-talk.

The structure of the Self-talk Inventory was examined using confirmatory factor analysis. Whereas exploratory factor analyses are adequate for the situations where links between the observed and latent variables are uncertain, confirmatory factor analyses minimize the impact of chance and are more appropriate for testing established theories (Byrne, 1998). In this study, negative cognitions were the focus to contrast the hypotheses derived from the tripartite model and the specificity theory. According to the tripartite model, all the negative cognitions should load on a general negative self-talk factor whereas, according to the specificity hypothesis, the distinctive cognitions of each affective disorder should load on different factors (i.e., Depressive Thoughts, Anxious Thoughts, and Angry Thoughts).

As a test of the criterion validity of the Self-Talk Inventory, we examined the relationship between self-talk dimensions and symptoms of three affective disorders (anxiety, depression, and anger). Regarding the valence of the cognitions, we posited the hypothesis that, according to previous research, SOM ratios and negative cognitions would show higher correlations with symptoms of affective disorders than would positive cognitions. We also examined the hypotheses derived from the specificity theory and tripartite model. According to the tripartite model, no specific cognitions would be associated with symptoms of each affective disorder, and the lack of positive cognitions, reflecting low positive affectivity, would be associated with depression but not with anxiety.

\section{Method}

\section{Participants}

The participants were 982 Spanish undergraduate students from three universities of the Basque Country. The final sample was made up of 376 men $(38.3 \%)$ and 598 women $(60.9 \%)$, but sex data were missing for 8 subjects $(0.8 \%)$. The mean age was $20.35(S D=2.16)$ years. The participants were selected by means of cluster sampling in order to achieve representativeness with regard to courses and type of study (e.g., Engineering, Psychology, Economics, Education, and Enterprise Administration and Direction).

\section{Measures}

Self-Talk Inventory (STI). This inventory includes two different scales: the Negative Self-Talk Scale and the Positive Self-Talk Scale. Participants were asked whether they would say to themselves each of 52 statements in response to 10 imaginary situations, using a 4-point response formatted scale $(1=$ not very probable, $2=$ somewhat probable, $3=$ 
quite probable, 4 = very probable). The items were obtained from the reports of an independent group of 110 students using a thought-listing procedure (Cacioppo, Hippel, \& Ernst, 1997). These students were asked to recall situations that made them feel happy, anxious, angry, or depressed, and to write down the thoughts that popped into their heads. Approximately 500 reports were obtained and we selected the most frequent positive and negative situations and the reported self-talk. Critical life events, such as the death of a relative, were not included. Self-talk that seemed peculiar or atypical was also excluded when selecting the items. An English translation of the resulting inventory is presented in Appendix $1^{1}$.

The Negative Self-Talk Scale. This scale includes three subscales that reflect three categories of thoughts: Anxious Thoughts (9 items), Depressive Thoughts (11 items), and Angry Thoughts (6 items). The Anxious-Thoughts category includes perceptions of external or internal danger and threat. The category of Depressive Thoughts includes negative selfevaluations, perceptions of rejection, and self-blame. Angry Thoughts reflect negative evaluations of other people's behavior and the intention to confront others.

The Positive Self-Talk Scale. This scale includes 26 items arranged in three subscales: Minimization (12 items), Coping Self-Instructions (4 items), and Positive Orientation (10 items). Minimization reflects a tendency to minimize problems or to offer an alternative view of them. Positive Orientation consists of self-statements reflecting optimism and positive evaluations of oneself or of circumstances. Coping Self-Instructions include cognitions aimed at directing thoughts or behavior positively and at influencing task control and completion.

We assigned the items of the STI to the six categories. To test the procedure, three independent psychologists were given the description of the six categories and asked to assign each item to the most appropriate subset. Inter-rater agreement was high, with a Kappa coefficient between .93 and .97 . To compute SOM ratios, scores from the STI were transformed to anchor them at zero $(1=0,2=1,3=2,4$ =3), following the proposals of Schwartz and Garamoni (1989) and Amsel and Fichten (1998). SOM ratios were computed by dividing positive self-statement scores by positive-plus-negative self-statement scores.

Center for Epidemiological Studies Depression Scale. The CES-D (Radloff, 1977) was used as a measure of depression symptoms. The CES-D consists of 20 statements rated on a 4-point Likert scale, ranging from 0 (rarely or none of the time) to 3 (most or all of the time). Previous research with the Spanish version of the CES-D has confirmed its factorial structure (Calvete \& Cardeñoso, 1999).
State-Trait Anxiety Inventory. The STAI (Spielberger, Gorsuch, \& Lushene, 1988) is a widely used measure of anxiety. The trait scale of the STAI is a 20 -item self-report measure of stable anxiety symptoms, such as feelings of fear and tension, and autonomic nervous system hyperactivity. Individuals rate each item using a 4-point response scale ranging from 1 (not at all) to 4 (very much so). Several studies have supported construct validity, testretest reliability, and adequate alpha coefficients for the Spanish version of the STAI (Spielberger et al., 1988).

The State-Trait Anger Expression Inventory (STAXI-2). The Trait-Anger Scale from the STAXI-2 (Spielberger, Miguel-Tobal, Casado, \& Cano-Vindel, 2000) was used as a measure of trait anger. It contains 10 items that assess the tendency to experience and express anger without any specific provocation. Participants score items using a 4-point response scale from 1 (not at all) to 4 (very much so). Previous studies have shown satisfactory psychometric properties for the Spanish version of the STAXI (Spielberger et al., 2000).

\section{Procedure}

The students filled in the questionnaires in a classroom setting. The questionnaires were presented in a packet so that participants could record their answers on a computer response-sheet. The participants completed the questionnaires anonymously and did not receive course credit for participation. The questionnaires took about 45 minutes to complete. Questionnaires were presented in the following order: STI, STAI, CES-D, and STAXI.

\section{Results}

\section{Measurement Models of the Self-Talk Inventory}

The parameters for confirmatory factor analysis were estimated using the covariance matrixes of the items from the STI. After testing that both the matrix and the distribution of the variables were adequate, the fit of the different models of this study was tested via maximum likelihood estimation with LISREL 8.52 (Jöreskog \& Sörbom, 2001). Following the recommendations from a number of authors (e.g., Hoyle \& Panter, 1995; Hu \& Bentler, 1998), goodness of fit was assessed by the Comparative Fit Index (CFI) and the NonNormed Fit Index (NNFI). In addition, the root mean square error of approximation (RMSEA) was used because it has been recommended as a basis for power analysis and model evaluation (MacCallum \& Hong, 1997). Generally, NNFI and CFI values of .90 or above reflect good fit, and RMSEA values lower than .10 indicate an adequate fit.

1 The Spanish version of the STI is available by contacting the authors. 
First, we tested the hypothesis that the STI structure could be represented by 6 correlated first-order factors (Model 1). The factor-loading matrix was full and fixed. Each item had a nonzero loading on the latent variable that it was designed to measure, and zero loading on the other factors. The error variance-covariance matrix was symmetrical, with diagonal elements free and off-diagonal elements fixed at zero. This model was a good fit to the data, $\chi^{2}(1259, N=982)=5285$, RMSEA $=.062, \mathrm{NNFI}=$ $.89, \mathrm{CFI}=.90$. Table 1 presents the factor loadings, which in all cases, were statistically different from zero ( $\mid T$-value $\mid$ $>$ 1.96). Next, we estimated two alternative models: a structure made up of two first-order-factors (Model 2: positive vs. negative thoughts), and a hierarchical model (Model 3), with two broad categories of self-talk (positive vs. negative thoughts) explaining covariances among the six specific categories of self-talk. Model 2 showed an inadequate fit to the data, $\chi^{2}(1273, N=982)=9839$, RMSEA $=.098, \mathrm{NNFI}=.77, \mathrm{CFI}=.78$. Model 3 obtained better fit indexes than Model $2, \chi^{2}(1267, N=982)=6804$, RMSEA $=.053, \mathrm{NNFI}=.89, \mathrm{CFI}=.89$. In this model, the factor loadings of Depressive Thoughts, Anxious Thoughts, and Angry Thoughts on Negative Thoughts were .99, .62, and .30, respectively. The factor loadings of Minimization, Positive Orientation, and Coping Self-Instructions on Positive Thoughts were $.92, .42$, and .53 , respectively. However, the comparison with Model 1 showed that Model 3 was untenable because it significantly increased the chi-squared value, $\Delta \chi^{2}(8, N=982)=1519, p<.001$.

Because the focus of this study was on the negative categories of self-talk, we estimated a series of additional confirmatory factor analyses with the Negative Self-Talk Scale to test the hypotheses concerning negative thoughts. The hypothesized model for this scale consisted of an oblique model with three first-order factors: Anxious Thoughts, Depressive Thoughts, and Angry Thoughts. This model provided a good fit to the data, $\chi^{2}(296, N=982)=1923$, RMESA $=.08$, NNFI $=.92$, and CFI $=.93$. Next, we estimated two alternative models of negative cognitions in order to compare them with the hypothesized model: a twofactor oblique structure in which anxiety-related thoughts and depression-related thoughts were included in the same factor, as predicted by the tripartite model of anxiety and depression, and a one-factor structure. The one-factor model did not fit the data adequately, $\chi^{2}(296, N=982)=4170$, RMSEA $=.14, \mathrm{NNFI}=.82, \mathrm{CFI}=.84$. The three-factor oblique model significantly reduced the value of chi-square in comparison to the two-factor model, $\chi^{2}(2, N=982)=$ $525, p<.0001$.

The alpha values and the correlation coefficients between the self-talk scores are displayed in Table 2. The Negative Self-Talk subscales were significantly intercorrelated, with the highest coefficient between Anxious Thoughts and Depressive Thoughts. The Positive Self-Talk subscales were also significantly intercorrelated. Although the correlation between the Positive Self-Talk Scale and the Negative SelfTalk Scale was near zero (.07), Minimization correlated negatively with Anxious Thoughts and Depressive Thoughts, and Angry Thoughts was associated positively with Positive Orientation and Coping Self-Instructions. The alpha coefficients for all the scales and subscales were adequate, except for Coping Self-Instructions.

Table 1

Factor Loadings of the Self-Talk Inventory

\begin{tabular}{|c|c|c|c|c|c|c|c|c|c|c|c|}
\hline \multicolumn{6}{|c|}{ Negative Self-Talk Scale } & \multicolumn{6}{|c|}{ Positive Self-Talk Scale } \\
\hline \multicolumn{2}{|c|}{ Depressive Thoughts } & \multicolumn{2}{|c|}{ Anxious Thoughts } & \multicolumn{2}{|c|}{ Angry Thoughts } & \multicolumn{2}{|c|}{ Minimization } & \multicolumn{2}{|c|}{ Positive Orientation } & \multicolumn{2}{|c|}{$\begin{array}{c}\text { Coping } \\
\text { Self-Instructions }\end{array}$} \\
\hline Item $\mathrm{Nr}$. & $\begin{array}{l}\text { Factor } \\
\text { loading }\end{array}$ & Item Nr. & $\begin{array}{l}\text { Factor } \\
\text { loading }\end{array}$ & Item Nr. & $\begin{array}{l}\text { Factor } \\
\text { loading }\end{array}$ & Item Nr. & $\begin{array}{l}\text { Factor } \\
\text { loading }\end{array}$ & Item Nr. & $\begin{array}{l}\text { Factor } \\
\text { loading }\end{array}$ & Item Nr. & $\begin{array}{l}\text { Factor } \\
\text { loading }\end{array}$ \\
\hline 1 & .52 & 5 & .54 & 23 & .63 & 4 & .40 & 34 & .39 & 8 & .39 \\
\hline 2 & .53 & 7 & .52 & 24 & .51 & 9 & .54 & 35 & .39 & 31 & .40 \\
\hline 3 & .46 & 19 & .44 & 25 & .80 & 13 & .43 & 36 & .41 & 43 & .62 \\
\hline 6 & .60 & 38 & .77 & 26 & .57 & 14 & .51 & 37 & .48 & 44 & .54 \\
\hline 10 & .61 & 39 & .77 & 27 & .83 & 15 & .46 & 46 & .44 & & \\
\hline 11 & .62 & 40 & .69 & 28 & .62 & 20 & .39 & 47 & .40 & & \\
\hline 12 & .57 & 41 & .75 & & & 21 & .41 & 48 & .40 & & \\
\hline 16 & .50 & 42 & .75 & & & 22 & .45 & 50 & .60 & & \\
\hline 17 & .56 & 49 & .45 & & & 29 & .39 & 51 & .69 & & \\
\hline 18 & .51 & & & & & 30 & .39 & 52 & .66 & & \\
\hline \multirow[t]{2}{*}{32} & .49 & & & & & 33 & .49 & & & & \\
\hline & & & & & & 45 & .51 & & & & \\
\hline
\end{tabular}




\section{Self-Talk Dimensions and Affective Problems}

Table 2 also presents the zero-order correlation coefficients among the Self-Talk scores and the symptoms of affective disorders. With the exception of Coping SelfInstructions, all the Self-Talk scores were associated significantly with symptoms of depression, anxiety, and anger. We used a $t$-test to examine the differences between pairs of correlation coefficients, following the procedure proposed by Cohen and Cohen $(1983)^{2}$. When total scores were examined, SOM ratio showed higher coefficients with symptoms of depression and anxiety than did Negative SelfTalk scores and Positive Self-Talk scores-that is, anxiety symptoms correlated higher with SOM ratio than with Negative Self-Talk scores, $t(979)=2.66, p<.01$-and anger correlated higher with total Negative Self-Talk scores than with SOM ratio, $t(979)=3.53, p<.01$. When subscales were examined, Depressive Thoughts correlated higher with symptoms of depression and anxiety than the total Negative Self-Talk scores, but similarly to the SOM ratio. In general, anger presented lower correlation coefficients with all SelfTalk scores than the other affective problems, showing the highest coefficient with the total Negative Self-Talk scores; for example, the coefficient between Negative Self-Talk scores and anger was higher than the coefficient between Depressive Thoughts and anger, $t(979)=3.53, p<.05$. Among the Positive Self-Talk subscales, Minimization had the highest correlation coefficient with symptoms of anxiety and depression, whereas anger correlated similarly with Positive Orientation and Minimization, $t(979)=0.05$, ns.

The correlation between symptoms of anxiety and depression was .70, and the correlations between anger and anxiety and depression were .43 and .32 , respectively. Given this overlap, the fit of the data to the specificity theory was examined using a multivariate strategy. We conducted a series of multiple regression analyses to determine which self-talk categories were associated with each of the measures of symptoms (depression, anxiety, and anger). Results are summarized in Table 3. In the first regression analysis, CESD scores were used as the criterion variable and Self-Talk subscales were entered simultaneously in the equation as predictor variables. The regression coefficients of Depressive Thoughts and Positive Orientation were statistically significant. Due to the high association between symptoms of depression, anxiety, and anger, the regression analysis was repeated with the anxiety and anger scores entered in the model as predictors in the first step, and the Self-Talk subscales in the second step. This provided an opportunity to assess the relative strength of the association between these Self-Talk subscales and depression while controlling the influence of the other two variables. Table 3 also shows the results of this analysis. The regression coefficients of Depressive Thoughts and Positive Orientation remained significant. In addition, Anxious Thoughts and Minimization showed significant but low regression coefficients. In a second set of regressions, anxiety scores were used as criterion variable and Self-Talk subscales

Table 2

Zero-order Correlations, Descriptive Statistics, and Alpha Coefficients of the Self-Talk Scores and Measures of Psychological Symptoms

\begin{tabular}{|c|c|c|c|c|c|c|c|c|c|c|c|c|c|c|c|c|}
\hline Scales & 1 & 2 & 3 & 4 & 5 & 6 & 7 & 8 & 9 & 10 & 11 & $M$ & $S D$ & Skewness & Kurtosis & $a$ \\
\hline 1. Depressive Thoughts & & & & & & & & & & & & 22.36 & 6.18 & 0.47 & -0.03 & .83 \\
\hline 2. Anxious Thoughts & .67 & & & & & & & & & & & 21.05 & 5.96 & 0.17 & -0.64 & .87 \\
\hline 3. Angry Thoughts & .26 & .18 & & & & & & & & & & 16.66 & 3.99 & -0.35 & -0.31 & .82 \\
\hline 4. Negative Self-Talk Scale & .89 & .86 & .51 & & & & & & & & & 60.07 & 12.47 & -0.03 & 0.19 & .90 \\
\hline 5. Minimization & -.39 & -.32 & .03 & -.34 & & & & & & & & 30.79 & 5.31 & -0.17 & -0.03 & .73 \\
\hline 6. Positive Orientation & .04 & -.004 & 4.20 & .08 & .35 & - & & & & & & 23.82 & 4.65 & 0.21 & -0.07 & .74 \\
\hline 7. Coping Self-Instructions & .10 & .07 & .38 & .19 & .43 & .37 & & & & & & 10.80 & 2.28 & -0.26 & 0.19 & .44 \\
\hline 8. Positive Self-Talk Scale & -.14 & -.14 & .23 & -.07 & .80 & .78 & .70 & & & & & 65.41 & 9.32 & 0.26 & -0.24 & .80 \\
\hline 9. $\mathrm{SOM}$ ratio & -.76 & -.75 & -.33 & -.84 & .66 & .34 & .13 & .57 & & & & 55.00 & 0.11 & -0.08 & 0.08 & - \\
\hline 10. Depression symptoms & .42 & .29 & .11 & .38 & -.30 & -.19 & -.04 & -.43 & -.25 & & & 18.13 & 9.73 & 0.91 & 1.18 & .90 \\
\hline 11. Anxiety symptoms & .54 & .44 & .12 & .51 & -.38 & -.15 & -.05 & -.55 & -.27 & .69 & & 18.20 & 7.71 & 0.57 & 0.02 & .88 \\
\hline 12. Anger symptoms & .31 & .23 & .26 & .34 & -.17 & .15 & .07 & -.28 & .01 & .31 & .39 & 22.16 & 4.97 & 0.38 & 0.10 & .81 \\
\hline
\end{tabular}

Note. All the correlation coefficients are statistically significant at $p<.0001$ except for those in boldface. Correlations between symptoms and self-talk scores are indicated in the framed cell.

\footnotetext{
2 The applicable formula is: $t=\left(\mathrm{r}_{\mathrm{xy}}-\mathrm{r}_{\mathrm{zy}}\right) * \operatorname{SQRT}\left[\left\{(\mathrm{N}-3)\left(1+\mathrm{r}_{\mathrm{xz}}\right)\right\} /\left\{2\left(1-\mathrm{r}_{\mathrm{xy}}{ }^{2}-\mathrm{r}_{\mathrm{xz}}{ }^{2}-\mathrm{r}_{\mathrm{zy}}{ }^{2}+2 \mathrm{r}_{\mathrm{xy}} * \mathrm{r}_{\mathrm{xz}} * \mathrm{r}_{\mathrm{xy}}\right)\right\}\right]$. This formula tests for a significant difference between the correlation between variables $\mathrm{X}$ and $\mathrm{Y}$ and the correlation between variables $\mathrm{Z}$ and $\mathrm{Y}$. The formula yields a $t$ statistic with $\mathrm{n}-3$ degrees of freedom.
} 
as predictors. Four Self-Talk subscales were significantly linked to anxiety symptoms: Depressive Thoughts, Anxious Thoughts, Minimization, and Positive Orientation. When the analysis was repeated with symptoms of depression and anger entered in the first step, the coefficient of Positive Orientation was nonsignificant. Lastly, the same procedure was performed to assess the association between the Self-Talk subscales and symptoms of anger. The coefficients of Depressive Thoughts, Angry Thoughts, Minimization, and Positive Orientation were significant. When anxiety and depression scores were entered in a first step, the regression coefficient of Depressive Thoughts was nonsignificant.
To further explore whether Self-Talk scores were associated with psychological symptoms at the clinical level, we used cut-off scores to identify participants with scores within the borderline or clinical range. Usually, CES-D scores higher than 16 are considered of clinical interest, whereas a cut-off of 30 indicates highly symptomatic individuals (Boyd, Weissman, Thompson, \& Myers, 1982). We compared participants within the clinical range (CESD-D scores $\geq 30$ ) with the normal group (CES-D scores < 16) in the Self-Talk subscales that showed significant coefficients in the above regression analyses. Table 4 presents the means and standard deviations of the cognitive variables in both groups. The

Table 3

Summary of Regression Analysis Testing the Association Between Self-Talk Subscales and Symptoms of Depression, Anxiety, and Anger

\begin{tabular}{|c|c|c|c|c|c|c|c|c|c|c|}
\hline \multirow[b]{2}{*}{ Outcome: Depression Symptor } & \multicolumn{5}{|c|}{ Analyses excluding the other symptoms from the model } & \multicolumn{5}{|c|}{ Analyses with the other symptoms included in the model } \\
\hline & ms $B$ & $S E$ & $\beta$ & $t$ & Step $R^{2}$ change & $B$ & $S E$ & $\beta$ & $t$ & Step $R^{2}$ change \\
\hline Step 1 & & & & & & & & & & $R^{2}=.50, F(2,761)=381^{* *}$ \\
\hline Anxiety & 0.70 & .04 & .66 & $19.40 * *$ & & & & & & \\
\hline Anger & 0.10 & .06 & .05 & 1.67 & & & & & & \\
\hline Step 2 & & & & & $R^{2}=.22, F(6,861)=41$ & & & & & $\Delta R^{2}=.02, F(6,755)=5^{* *}$ \\
\hline Depressive Thoughts & 0.62 & .07 & .38 & $9.38 * *$ & & 0.21 & .06 & .13 & $3.58 * *$ & \\
\hline Anxious Thoughts & 0.01 & .07 & .00 & 0.00 & & -0.12 & .06 & $-.07-$ & $-2.15^{*}$ & \\
\hline Angry Thoughts & 0.15 & .08 & .06 & 1.85 & & 0.01 & .07 & .01 & 0.04 & \\
\hline Minimization & -0.13 & .07 & $-.07-$ & -1.82 & & 0.13 & .06 & .07 & $2.05^{*}$ & \\
\hline Positive Orientation & -0.42 & .07 & $-.20-$ & $-5.82 * *$ & & -0.27 & .06 & $-.12-$ & $-4.33 * *$ & \\
\hline Coping Self-Instructions & 0.01 & .15 & .01 & 0.09 & & -0.09 & .13 & $-.02-$ & -0.68 & \\
\hline Outcome: Anxiety Symptom & $n s \quad B$ & $S E$ & $\beta$ & $t$ & Step $R^{2}$ change & $B$ & $S E$ & $\beta$ & $t$ & Step $R^{2}$ change \\
\hline Step 1 & & & & & & & & & & $R^{2}=.54, F(2,761)=454^{* *}$ \\
\hline Depression & 0.46 & .02 & .511 & $19.40 * *$ & & & & & & \\
\hline Anger & 0.32 & .05 & .17 & $6.73 * *$ & & & & & & \\
\hline Step 2 & & & & & $R^{2}=.34, \quad F(6,904)=77$ & & & & & $\Delta R^{2}=.08, F(6,755)=28^{* *}$ \\
\hline Depressive Thoughts & 0.60 & .06 & .401 & $10.87 * *$ & & 0.21 & .05 & .14 & $4.39 * *$ & \\
\hline Anxious Thoughts & 0.20 & .06 & .13 & $3.58 * *$ & & 0.21 & .05 & .13 & $4.64 * *$ & \\
\hline Angry Thoughts & 0.07 & .07 & .03 & 1.07 & & -0.01 & .06 & -.01 & -.013 & \\
\hline Minimization & -0.26 & .06 & $-.15-$ & $-4.39 * *$ & & -0.23 & .05 & $-.13-$ & $-4.55 * *$ & \\
\hline Positive Orientation & -0.24 & .06 & $-.12-$ & $-3.91 * *$ & & -0.08 & .05 & $-.04-$ & -1.49 & \\
\hline Coping Self-Instructions & 0.10 & .13 & .03 & 0.80 & & 0.11 & .11 & .03 & 1.03 & \\
\hline Outcome: Anger & $B$ & $S E$ & $\beta$ & $t$ & Step $R^{2}$ change & $B$ & $S E$ & $\beta$ & $t$ & Step $R^{2}$ change \\
\hline Step 1 & & & & & & & & & & $R^{2}=.19, F(2,761)=87 * *$ \\
\hline Anxiety & & & & & & 0.18 & .03 & .34 & $6.73 * *$ & \\
\hline Depression & & & & & & 0.04 & .02 & .08 & 1.67 & \\
\hline Step 2 & & & & & $R^{2}=.16, F(6,898)=29$ & & & & & $\Delta R^{2}=.08, F(6,755)=13^{* *}$ \\
\hline Depressive Thoughts & 0.14 & .03 & .17 & $4.05^{* *}$ & & 0.02 & .04 & .03 & 0.62 & \\
\hline Anxious Thoughts & 0.03 & .03 & .04 & 1.00 & & -0.01 & .04 & $-.01-$ & -0.27 & \\
\hline Angry Thoughts & 0.23 & .04 & .18 & $5.69 * *$ & & 0.21 & .04 & .17 & $5.04 * *$ & \\
\hline Minimization & -0.16 & .04 & $-.17-$ & $-4.39 * *$ & & -0.10 & .04 & $-.10-$ & $-2.53^{*}$ & \\
\hline Positive Orientation & 0.17 & .04 & .16 & $4.67 * *$ & & 0.21 & .04 & .20 & $5.53 * *$ & \\
\hline Coping Self-Instructions & -0.01 & .08 & $-.01-$ & -0.08 & & 0.01 & .08 & .01 & 0.03 & \\
\hline
\end{tabular}

Note. $* p<.05, * * p<.001$ 
analysis of variance revealed statistically significant differences in all variables. Cohen (1988) proposed small, medium, and large effect sizes $(.2, .5$, and .8$)$ as a guide to interpret results. Using this guideline, a large effect was found for Depressive Thoughts, and medium effects were found for Anxious Thoughts and Minimization. For anxiety and anger symptoms, participants within the normal range (percentile $<75$ ) and clinical range (percentile $>90$ ) were compared ${ }^{3}$. Differences between subgroups in anxiety scores were large in all cognitive variables, whereas differences between subgroups in anger were large only in Angry Thoughts.

\section{Discussion}

The aim of this study was to develop an inventory to assess self-talk in young people from nonclinical populations, and to study the relation between thoughts and symptoms of affective disorders that derives from cognitive models. This inventory consists of two scales: the Negative Self-Talk Scale and the Positive Self-Talk Scale, and has the following characteristics: First, it assesses self-talk concurrently by using ten imaginary situations. Second, both the situations and the self-statements were obtained from true reports from a previous group of 110 students. Third, the negative selftalk categories are based on the cognitive content-specificity theory (Beck et al., 1987), and the positive categories reflect self-talk dimensions that were previously reviewed in the literature (Calvete \& Cardeñoso, 2002; Kendall \& Chansky, 1991; Prins \& Hanewall, 1997). Fourth, the adequacy of including the items in the categories was based on inter-rater agreement. And last, the Positive Self-Talk Scale has the same number of items as the Negative Self-Talk Scale in order to facilitate estimation of SOM-ratios.

The results confirmed the hypothesized six-factor structure of the Self-talk Inventory (Depressive Thoughts, Anxious Thoughts, Angry Thoughts, Minimization, Positive Orientation, and Coping Self-Instructions). In addition, findings concerning the structure of the Negative Self-Talk Scale provided support for the cognitive content-specificity hypothesis, because the confirmatory factor analyses showed that a three-factor model (Angry Thoughts, Anxious Thoughts, and Depressive Thoughts)

Table 4

Differences in Cognitive Variables between Normal, Borderline, and Clinical Subgroups

Subgroups for depression symptoms

Normal range, $n=462$ Clinical range, $n=122$

\begin{tabular}{lcccccc}
\hline & $M$ & $S D$ & $M$ & $S D$ & $F(1,582)$ & Effect Size \\
\hline Depressive thoughts & 20.34 & 5.49 & 26.71 & 6.81 & $116.83^{* *}$ & -1 \\
Anxious Thoughts & 19.62 & 5.53 & 23.29 & 6.70 & $38.70^{* *}$ & -0.63 \\
Minimization & 31.73 & 5.26 & 28.73 & 5.45 & $30.97 * *$ & 0.57 \\
Positive Orientation & 24.34 & 4.77 & 22.69 & 4.91 & $11.44^{* *}$ & 0.34 \\
\hline
\end{tabular}

Subgroups for anxiety symptoms

Normal range, $n=642$ Clinical range, $n=76$

\begin{tabular}{lccccrr}
\hline & $M$ & $S D$ & $M$ & $S D$ & $F(1,724)$ & Effect Size \\
\hline Depressive Thoughts & 20.90 & 5.48 & 29.76 & 6.54 & $170.11^{* *}$ & -1.58 \\
Anxious Thoughts & 19.90 & 5.47 & 25.97 & 6.09 & $81.76^{* *}$ & -1.10 \\
Minimization & 31.68 & 5.05 & 26.32 & 5.38 & $75.62^{* *}$ & 1.10 \\
\hline
\end{tabular}

Subgroups for anger symptoms

Normal range, $n=632$ Clinical range, $n=102$

\begin{tabular}{lcccccr}
\hline & $M$ & $S D$ & $M$ & $S D$ & $F(1,732)$ & Effect Size \\
\hline Angry Thoughts & 16.14 & 3.92 & 19.15 & 3.67 & $52.48^{* *}$ & -0.77 \\
Minimization & 31.16 & 5.18 & 29.37 & 5.68 & $10.14^{*}$ & 0.34 \\
Positive Orientation & 23.59 & 4.60 & 25.50 & 5.01 & $14.80^{* *}$ & -0.41 \\
\hline
\end{tabular}

Note. A negative effect size indicates a higher score for the clinical subgroup.

$* p<.05 . * * p<.001$.

3 We used cut-off scores obtained in Spanish samples for the STAI and STAXI (Spielberger et al., 1988, 2000). 
fit the data better than did the one- (Negative Cognitions) or two-factor (Angry and Anxious-Depressive Thoughts) models. The latter two would have supported the tripartite model of anxiety and depression. Our results are consistent with the findings of Burns and Eidelson (1998) when they studied the factor structure of the items to measure anxiety and depression. Alpha coefficients were adequate for all the subscales of the inventory except in the case of the Coping Self-Instructions subscale. Future research with the STI should not only confirm the structure of the instrument in different samples but also improve the Coping Self-Instructions subscale.

Regarding the relation between categories of self-talk, we highlight the following conclusions: First, in this study, no correlation was obtained between the total scores of positive and negative self-talk, in contrast to the results of other studies in which a low negative correlation was observed between both types of self-talk (Burgess \& Haaga, 1994; Calvete \& Cardeñoso, 2002; Calvete \& Connor-Smith, 2005; Ingram et al., 1995; McDermut \& Haaga, 1994). However, the analysis of the correlations between the subscales indicated that the subscale of Minimization was negatively related to depressionand anxiety-related cognitions, and that anger-related cognitions were positively associated with Positive Orientation and Coping Self-Instructions. The latter result may be masking the relation between the total scores on Negative Self-Talk Scales and Positive Self-Talk Scales, because most of the current scales to study self-talk do not include anger-related cognitions. Second, Depressive Thoughts and Anxious Thoughts were highly correlated. This correlation is consistent with the overlap between depression and anxiety (Clark \& Watson, 1991). Last, the results concerning Coping SelfInstructions are mixed. On the one hand, this subscale correlates positively with the other two Positive Self-Talk subscales, but, on the other hand, it also correlates positively with the Angry Thoughts and Depressive Thoughts. This result underscores the problem when conceptualizing this type of self-talk, which has already been reported in other studies. For example, Kendall and Chansky (1991) suggested that coping self-instructions could be a negative thought category. Nevertheless, the low consistency of this subscale precluded drawing any robust conclusions.

As a way of testing the empirical validity of the STI, we assessed the relationships between the Self-Talk scores and symptoms of affective disorders. Regarding the hypothesis about the valence of thoughts, our results indicated that both SOM ratios and negative self-talk were more closely associated with the psychological symptoms than was positive self-talk. This result is consistent with other previous studies (Calvete \& Connor-Smith, 2005; Treadwell \& Kendall, 1996). The subscales based on cognitive content were employed to study the specificity hypothesis. Similarly to previous studies, our results revealed the difficulty of evaluating the theory of cognitive specificity, given the high degree of overlap among affective problems. We tried to examine this theory by means of multiple regression analyses, controlling statistically the effect of the variables that could be confounding the results. In accordance with this strategy, in the case of depression, the data were congruent with the cognitive specificity theory, because symptoms of depression were mainly associated with a higher presence of depressive cognitions, whereas angry and anxious cognitions seemed irrelevant. On the other hand, the results for symptoms of anxiety were not congruent with the theory of cognitive specificity, because anxiety scores were associated with both anxious cognitions and depressive cognitions. Hence, depressive self-statements were not uniquely associated with symptoms of depression. This result is similar to that obtained by Lerner et al. (1999) with children. Lastly, in the case of anger, although modest, our results also tend to support the specificity hypothesis. When the influence of symptoms of anxiety and depression were controlled, angry cognitions were the only type of negative thought associated with anger.

The results concerning the Positive Orientation subscale provided support for the tripartite model. This subscale reflects optimism and a positive view, which could be conceptualized as the cognitive dimension of positive affect. When the overlap between psychological problems was controlled, there was no association between Positive Orientation and symptoms of anxiety, whereas there was an association between symptoms of depression and Positive Orientation. This result is consistent with the tripartite model, which states that positive affect is unique to depression and irrelevant to anxiety (Clark et al., 1990), and is congruent with the results of other studies. For example, Burgess and Haaga (1994) also found that positive self-statements showed strong negative associations with depression rather than with anxiety. In addition, as in our study, Jolly and Wiesner (1996) observed that when the depression score was controlled, anxiety and positive affect were not associated. Moreover, in this study, we found that the three affective problems were different with regard to this type of self-talk: Positive Orientation correlated positively with anger, negatively with symptoms of depression, and was not significantly associated with symptoms of anxiety. The correlation between Positive Orientation and anger is in accordance with the results of several studies about the cognitive characteristics of aggressive individuals, which indicate that aggressive behavior could be linked to an unusual endorsement of positive affect in several settings (Edens et al., 1999; Lochman \& Dodge, 1994). All these results suggest that, although negative thinking and the SOM ratio are more predictive of psychological maladjustment, positive thinking may be the most promising for discriminating between different emotional disorders.

This study has a number of shortcomings. First, although overall characteristics of the STI are adequate, it presents limitations that should be improved in future versions of the inventory. For example, the Coping Self-Instructions subscale exhibited poor internal consistency, likely due to the insufficient number of items. Moreover, the number of items in the subscales was unevenly distributed across 
situations, and, from a psychometric perspective, this unbalanced number of categories of self-talk per situation could affect the strength of the measure negatively. However, the solution to this problem is complex because the results of the thought-listing procedure indicated that each type of situation was more likely linked to some types of self-talk than to others. This result is consistent with the structure of the BSTI (Burnett, 1996), which also was developed from thought-listing and presents a similar unbalanced number of categories. Second, the measure of anxiety employed (STAI) includes items such as blue mood, crying, and unhappiness, which may be more characteristic of depression, and, consequently, may have confounded the results about the lack of specificity for anxiety. Third, the content overlap between measures could inflate the association between negative self-talk categories and symptoms of affective problems (McPherson \& Lakey, 1993), leading to a biased superiority of negative thinking to predict psychological problems ${ }^{4}$. Last, although university students are the focus of several studies, it is necessary to confirm the validity of the STI when used in different samples, including clinical samples. Although we tried to examine whether Self-Talk scores were associated with psychological problems at the clinical level, this approach was only tentative, and participants who scored above the predetermined cut-off levels on the screening measures should be interviewed more specifically for a diagnosis of affective disorders.

In summary, the instrument developed in this research has some positive characteristics, such as the inclusion of several categories of self-talk and its factorial structure, which future research should confirm. On the other hand, this study offers mixed results about the specificity hypothesis and emphasizes the role of positive thinking in the differentiation of depression, anxiety, and anger.

\section{References}

Amsel, R., \& Fichten, C. (1998). Recommendations for selfstatements inventories: Use of valence, end points, frequency, and relative frequency. Cognitive Therapy and Research, 22, 255-277.

Beck, A.T. (1976). Cognitive therapy and the emotional disorders. Madison, WI: International Universities Press.

Beck, A.T., Brown, G., Steer, R.A., Eidelson, J.T., \& Riskind, J.H. (1987). Differentiating anxiety and depression: A test of the cognitive content-specificity hypothesis. Journal of Abnormal Psychology, 96, 179-183.

Boyd, J.H., Weissman, M.M., Thompson, D., \& Myers, J.K. (1982). Screening for depression in a community sample. Archives of General Psychiatry, 39, 1195-1200.
Burgess, E., \& Haaga, D.A.F. (1994). The Positive Automatic Thoughts Questionnaire- Revised: Equivalent measures of positive thinking? Cognitive Therapy and Research, 18, 15-24.

Burnett, P.C. (1996). Children's self-talk and significant others' positive and negative statements. Educational Psychology, 16, 57-67.

Burns, D.D., \& Eidelson, R.J. (1998). Why are depression and anxiety correlated? A test of the tripartite model. Journal of Consulting and Clinical Psychology, 66, 461-473.

Byrne, B. (1998). Structural equation modeling with LISREL, PRELIS, and SIMPLIS: Basic concepts, applications, and programming. Mahwah, NJ: Erlbaum.

Cacioppo, J.T., Hippel, W., \& Ernst, J.M. (1997). Mapping cognitive structures and processes through verbal content: The thoughtlisting technique. Journal of Consulting and Clinical Psychology, 65, 928-940.

Calvete, E., \& Cardeñoso, O. (1999). Creencias y síntomas depresivos: Resultados preliminares en el desarrollo de una escala de creencias irracionales abreviada. Anales de Psicología, 15, 179-190.

Calvete, E., \& Cardeñoso, O. (2002). Self-talk in adolescents: Dimensions, States of Mind, and psychological maladjustment. Cognitive Therapy and Research, 26, 473-485.

Calvete, E., \& Connor-Smith, J. (2005). Automatic thoughts and psychological symptoms: A Cross-Cultural Comparison of American and Spanish students. Cognitive Therapy and Research, 29, 201-207.

Clark, D.A., Beck, A.T., \& Brown, G. (1989). Cognitive mediation in general psychiatric outpatients: A test of the contentspecificity hypothesis. Journal of Personality and Social Psychology, 56, 958-964.

Clark, D.A., Beck, A.T., \& Steward, B. (1990). Cognitive specificity and positive-negative affectivity: Complementary or contradictory views on anxiety and depression? Journal of Abnormal Psychology, 99, 148-155.

Clark, D.A., Steer, R.A., \& Beck, A.T. (1994). Common and specific dimensions of self-reported anxiety and depression: Implications for the cognitive and tripartite models. Journal of Abnormal Psychology, 103, 645-654.

Clark, L.A., \& Watson, D. (1991). Tripartite model of anxiety and depression: Psychometric evidence and taxonomic implications. Journal of Abnormal Psychology, 100, 316-336.

Cohen, J. (1988). Statistical power analysis for the behavioral sciences $\left(2^{\text {nd }}\right.$ ed.) Hillsdale, NJ: Erlbaum.

Cohen, J., \& Cohen, P. (1983). Applied multiple regression/correlation analysis for the behavioral sciences. Hillsdale, NJ: Erlbaum.

Dodge, K.A., \& Crick, N.R. (1990). Social information processing bases of aggressive behavior in children. Personality and Social Psychology Bulletin, 16, 8-22.

Edens, J.F., Cavell, T.A., \& Hughes, J.N. (1999). The self-systems of aggressive children: A cluster-analytic investigation. Journal of Child Psychology and Psychiatry, 40, 441-453.

4 This suggestion was proposed by an anonymous reviewer. 
Glass, C.R., \& Arnkoff, D.B. (1997). Questionnaire methods of cognitive self-statement assessment. Journal of Consulting and Clinical Psychology, 65, 911-927.

Haaga, D.A.F. (1997). Introduction to the special section on measuring cognitive products in research and practice. Journal of Consulting and Clinical Psychology, 65, 907-910.

Hoyle, R.H., \& Panter, A.T. (1995). Writing about structural equation models. In R.H. Hoyle (Ed.), Structural equation modeling. Concepts, issues, and applications. London: Sage.

Hu, L. \& Bentler, P.M. (1998). Fit indices in covariance structure modeling: Sensitivity to underparameterized model misspecification. Psychological Methods, 3, 424-453.

Ingram, R.E., Kendall, P.C., Siegle, G., Guarino, J., \& McLaughlin, S.C. (1995). Psychometric properties of the Positive Automatic Thoughts Questionnaire. Psychological Assessment, 7, 495507.

Ingram, R.E., Kendall, P.C., Smith, T.W., Donnell, C., \& Ronan, K. (1987). Cognitive specificity in emotional distress. Journal of Personality and Social Psychology, 53, 734-742.

Jolly, J.B., \& Kramer, T.A. (1994). The hierarchical arrangement of internalizing cognitions. Cognitive Therapy and Research, $18,1-14$.

Jolly, J.B., \& Wiesner, D.C. (1996). Psychometric properties of the Automatic Thoughts Questionnaire-Positive with inpatient adolescents. Cognitive Therapy and Research, 20, 481-498.

Jöreskog, K.G., \& Sörbom, D. (2001). LISREL8 user's reference guide ( $2^{\text {nd }}$ ed.). Lincolnwood, IL: Scientific Software International.

Kendall, P.C. (1984). Behavioral assessment and methodology. In G.T. Wilson, C.M. Franks, K.D. Brownell, \& P.C. Kendall (Eds.), Annual review of behavior therapy: Theory and practice (Vol. 9, pp. 39-94). New York: Guilford Press.

Kendall, P.C., \& Chansky, T.E. (1991). Considering cognition in anxiety-disordered children. Journal of Anxiety Disorders, 5, 167-185.

Kendall, P.C. \& Hollon, S.D. (1989). Anxious self-talk: Development of the Anxious Self-Statements Questionnaire (ASSQ). Cognitive Therapy and Research, 4, 383-395.

Kendall, P.C., Howard, B.L., \& Hays, R.C. (1989). Self-referent speech and psychopathology: The balance of positive and negative thinking. Cognitive Therapy and Research, 13, 583598.

Lerner, J., Safren, S.A., Henin, A., Warman, M., Heimberg, R.G., \& Kendall, P.C. (1999). Differentiation of anxious and depressive self-statements in youth: Factor structure of the Negative Affect Self-Statement Questionnaire among youth referred to an anxiety disorders clinic. Journal of Clinical Child Psychology, 28, 82-93.

Lochman, J.E., \& Dodge, K.A. (1994). Social-cognitive processes of severely violent, moderately aggressive, and nonaggressive boys. Journal of Consulting and Clinical Psychology, 62, 366374.

MacCallum, R. \& Hong, S. (1997). Power analysis in covariance structure modeling using GFI and AGFI. Multivariate Behavioral Research, 32, 193-210.
McDermut, W., \& Haaga, D.A.F. (1994). Cognitive balance and specificity in anxiety and depression. Cognitive Therapy and Research, 18, 333-352.

McPherson, L., \& Lakey, B. (1993). Content overlap inflates the relation between negative cognition and dysphoria. Journal of Personality Assessment, 60(2), 411-7.

Prins, P.J., \& Hanewald, G.J.F.P. (1997). Self-statements of testanxious children: Thought-listing and questionnaire approaches. Journal of Consulting and Clinical Psychology, 65, 440-447.

Radloff, L.S. (1977). The CES-D Scale: A self-report depression scale for research in the general population. Applied Psychological Measurement, 1, 385-401.

Ronan, K.R., \& Kendall, P.C. (1997). Self-talk in distressed youth: States-of-mind and content specificity. Journal of Clinical Child Psychology, 4, 330-337.

Ronan, K.R., Kendall, P.C., \& Rowe, M. (1994). Negative affectivity in children: Development and validation of a selfstatement questionnaire. Cognitive Therapy and Research, 18, 509-528.

Safren, S.A., Heimberg, R.G., Lerner, A.H., Warman, M., \& Kendall, P.C. (2000). Differentiating anxious and depressive self-statements: Combined factor structure of the Anxious SelfStatements Questionnaire and the Automatic Thoughts Questionnaire-Revised. Cognitive Therapy and Research, 24, 327-344.

Schwartz, R.M. (1997). Consider the simple screw: Cognitive science, quality improvement, and psychotherapy. Journal of Consulting and Clinical Psychology, 65, 970-983.

Schwartz, R. M., \& Garamoni, G.L. (1986). A structural model of positive and negative states of mind: Asymmetry in the internal dialogue. In P.C. Kendall (Ed.), Advances in cognitivebehavioral research and therapy (Vol. 5, pp. 1-62). New York: Academic Press.

Schwartz, R.M., \& Garamoni, G.L. (1989). Cognitive balance and psychopathology: Evaluation of an information processing model of positive and negative states of mind. Clinical Psychology Review, 9, 271-294.

Spielberger, C.D., Gorsuch, R.I., \& Lushene, R.E. (1988). STAI. Cuestionario de Ansiedad Estado-Rasgo: Manual. Madrid: TEA.

Spielberger, C.D., Miguel-Tobal, J.J., Casado, M.I., \& Cano-Vindel, A. (2000). Inventario de Expresión de Ira Estado-Rasgo-STAXI. Madrid: TEA.

Steer, R.A., Clark, D.A., Beck, A.T., \& Ranieri, W.F. (1995). Common and specific dimensions of self-reported anxiety and depression: A replication. Journal of Abnormal Psychology, $104,542-545$.

Treadwell, K.R.H., \& Kendall, P.C. (1996). Self-talk in youth with anxiety disorders: States of mind, content specificity, and treatment outcome. Journal of Consulting and Clinical Psychology, 64, 941-950.

Received: June 5, 2004 Revision received: December 2, 2004 Accepted: January 15, 2005 


\section{Appendix 1}

SelF-TALK INVENTORY

Below are presented a series of scenarios and some thoughts that people may have. Please try to imagine yourself as realistically as possible in each of these situations and indicate the probability with which you would endorse each of the thoughts, using the following scale:

$1=$ not very probable, $2=$ somewhat probable, $3=$ quite probable, $4=$ very probable

* Your friends went out to a party last Saturday and on Monday, you hear them remarking what fun they had, but nobody had told you that they were going out. Then, you think:

1. I feel rejected.

2. They don't want me in their group; they are better off without me.

3. It's my own fault; I must have done something wrong.

4. Surely, they didn't realize it and they didn't do it on purpose.

* You see the bus arriving and run to catch it. When you are two meters away and the doors have just opened, the people in line pile up at the doors, and you slip and fall down. Then, you think:

5. I feel so embarrassed.

6. They sure must think I'm clumsy.

7. I wish I could just disappear!

8. I must try to do things without hurrying.

9. This can happen to anyone.

* You come across a boy/girl you have met recently and whom you have bumped into several times. You say "hello" but he/she doesn't respond. Then you think:

10. I'm not interesting enough.

11. I'm sure that he/she doesn't like me.

12. Everybody ignores me.

13. I'm sure he/she did not hear me.

14. Take it easy, there's an explanation for everything.

15. I shouldn't let it bother me.

* You are at home and you put on an old tracksuit to go down and buy some bread. As you leave your house, you bump into a university classmate whom you have recently met. Then, you think:

16. I look terrible.

17. I'm sure he/she is thinking how awful I look.

18. I should be more careful about my appearance.

19. He/She is going to laugh at me.

20. I don't care, I feel O.K.

21 . He/She probably didn't even notice what I was wearing.

22. It doesn't matter, some other day he/she will see me looking better.

* A person from your (academic) group did not do the tasks he/she was supposed to do. This is not the first time that this person does not do his/her share. Then, you think:

23. He/She always waits for me to do it.

24. As soon as he/she arrives, I'm going to tell him/her what I think.

25. I'm fed up!
26. I'm sure that I will have to end up doing his/her work.

27. What nerve! He/she always does the same thing.

28. He/She should collaborate with the rest.

29. Maybe there is something wrong, or he/she has some problem?

30. It's not so important. He/she will eventually do his/her share.

* You arrive at the bus stop just when the bus is leaving and you miss it. The next bus will take an hour to arrive. Then, you think:

31. What can I do now? Maybe I can read something, or go and see the shop-windows...

32. I always have such rotten luck.

33. Oh, well, it's not so bad.

* They just tell you that you passed the exam you took last week. Then, you think:

34. If I can pass that exam, I can pass the rest of the exams.

35. It was worth the effort.

36. I must go and tell everyone...

37. I'm cool!

* You have to expound a work in front of the class. Then, you think:

38. I'll blush and everyone will realize how nervous I am.

39. I'm sure I'll make a mistake and say something foolish.

40. I'm sure everyone will think I'm an idiot.

41. How awful! What an embarrassing situation!

42. I feel terrible!

43. Calm down, think a bit and don't get blocked.

44. If I don't think about all the people out there, I will do a better job.

45. I'll do a good job. There's no reason why I shouldn't.

* When you get home, they tell you that a friend from whom you haven't heard lately has phoned you. Then, you think:

46. For some reason, I impress people.

47. This is wonderful!

48. My friend is great: two months without seeing each other and it seems that nothing has changed.

* At a family meal, your mother (or someone else with whom you live) tells your relatives how proud she is of you because of all your efforts at your studies and of your other positive qualities. Then, you think:

49. My God, how embarrassing! I'm sure I must be blushing like $\operatorname{mad} . .$.

50. Well, modesty aside, the truth is that I deserve it.

51. They're all so proud of me!

52. I feel great! 